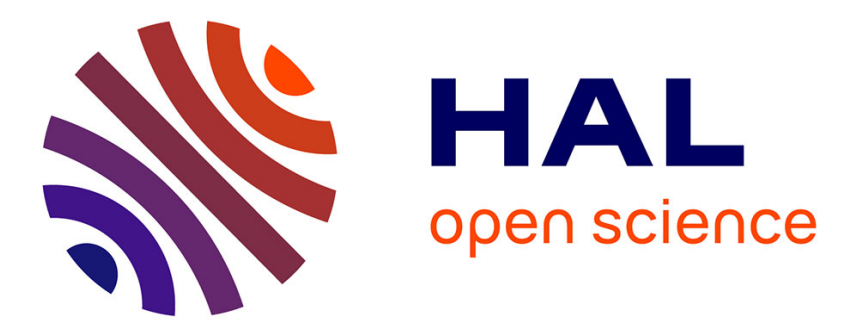

\title{
Relevance of early CT scan diagnosis of blunt diaphragmatic injury: A retrospective analysis from the Northern French Alps Emergency Network
}

\author{
A. Mancini, A. Duramé, S. Barbois, J. Abba, F.-X. Ageron, C. Arvieux
}

\section{- To cite this version:}

A. Mancini, A. Duramé, S. Barbois, J. Abba, F.-X. Ageron, et al.. Relevance of early CT scan diagnosis of blunt diaphragmatic injury: A retrospective analysis from the Northern French Alps Emergency Network. Journal of Visceral Surgery, 2019, 156, pp.3 - 9. 10.1016/j.jviscsurg.2018.10.005 . hal03486527

\section{HAL Id: hal-03486527 \\ https://hal.science/hal-03486527}

Submitted on 20 Dec 2021

HAL is a multi-disciplinary open access archive for the deposit and dissemination of scientific research documents, whether they are published or not. The documents may come from teaching and research institutions in France or abroad, or from public or private research centers.
L'archive ouverte pluridisciplinaire HAL, est destinée au dépôt et à la diffusion de documents scientifiques de niveau recherche, publiés ou non, émanant des établissements d'enseignement et de recherche français ou étrangers, des laboratoires publics ou privés.

\section{(ㅇ)(1) $\$$}

Distributed under a Creative Commons Attribution - NonCommerciall 4.0 International 
Intérêt du diagnostic scannographique précoce dans les ruptures post traumatismes fermés du diaphragme : analyse rétrospective de l'expérience du Trauma System du réseau nord-alpin des urgences.

Relevance of early CT scan diagnosis of blunt diaphragmatic injury: a retrospective analysis from the Northern French Alps Emergency Network

Adrian Mancini ${ }^{1}$, Adrien Duramé ${ }^{1}$, Sandrine Barbois ${ }^{1}$, Julio Abba ${ }^{1}$, François-Xavier Ageron ${ }^{2}$, Catherine Arvieux ${ }^{1}$

${ }^{1}$ Service de Chirurgie Digestive et de l'urgence, CHU Grenoble-Alpes, France

${ }^{2}$ Urgences SAMU-SMUR, CH Annecy-Genevois, France

Auteur correspondant : Pr Catherine Arvieux, Service de Chirurgie Digestive et de l'urgence, CHU Grenoble-Alpes, CS 102017, 38043 Grenoble cedex, France.

Mail : CArvieux@chu-grenoble.fr 
Acknowledgements: the authors thank Fahd Bennani MD for his illustrations

Conflict of interests: none of the authors have any conflicts of interest to declare

Introduction

Post-traumatic diaphragmatic ruptures occur rarely, the incidence having been estimated between 0.7 and $8 \%$ of all blunt thoraco-abdominal trauma [1-4]. The first descriptions date from the $16^{\text {th }}$ century: in 1541 Sennertus reported a case of intra-thoracic migration of abdominal organs through a diaphragmatic rupture, and in 1579, Amboise Paré described the first "delayed complication" of diaphragmatic rupture when he performed an autopsy in a young captain of the French Artillery, who had survived a firearm penetrating injury to the abdomen. He died eight months later because of necrosis due to strangulated colon through the diaphragmatic rupture [5]. Paré also described a patient with a strangulated stomach after blunt trauma [6]. The mechanism of injury implies a sudden change in the pressure between the thorax and the abdomen or a tear of the diaphragmatic attachments [7], explaining why traumatic ruptures of the diaphragm are classically found after high-energy blunt trauma. This also explains why there are often several associated thoracic, abdominal and/or pelvic injuries [4] and why it is considered a factor of severity in the multiple trauma setting [8]. Diagnosis is difficult: clinical signs 
are often respiratory and therefore not specific [9], chest X-rays do not perform well, as they are falsely negative in $48 \%$ of cases, and CT scans can be misleading, even if this is the investigation of choice [10]. For blunt trauma, non-operative management has become the standard management, which no longer allows correcting a missed diagnosis during operation. The delay in diagnosis can range from a few days to several months or even years after the initial trauma [11]. The low incidence of this injury explains why there are many isolated case reports but only two large French series reported before 2000 $[12,13]$

The Northern Alpine Emergency Network (REseau Nord Alpin des Urgences (RENAU)) was created in 2001 upon request of the Regional Health Agency with the goal of harmonizing practices and establishing emergency management algorithms. This network congregates 24 institutions in the Rhône-Alpes region of France and has allowed the set up of several health care procedures and inter-institutional transfers, in particular for multiple trauma patients. This network has also allowed for performance of several large sample studies, thanks to the "TRENAU" epidemiology registry in traumatology. All the institutions in this network follow a specific algorithm dedicated to the management of multiple trauma victims, essentially based on whole body CT 
scan [14]. The management of suspected diaphragmatic ruptures is codified in the algorithm presented in Figure 1.

The goal of this retrospective study was to describe a series of patients managed for diaphragmatic rupture following blunt trauma seen in the trauma unit of the University Hospital of Grenoble and RENAU, and to discuss the modalities of early CT scan diagnosis and management.

\section{Patients and methods}

All patients with the diagnosis of diaphragmatic rupture seen in the trauma unit of the University Hospital of Grenoble and RENAU institutions between 2009 and 2017 were identified using the operating room software programs, medical procedure coding system and the TRENAU registry. A specific protocol based on CT imaging for multiple injury is used in all institutions in the network. The management algorithm can be seen in Figure 1. Patients with penetrating trauma were not included. Demographic characteristics, mechanisms of injury, clinical presentations, diagnostic modalities, thoracic CT and radiographic findings, associated injuries, surgical treatment and post-operative outcomes were analyzed. The timing of management and interval before operation were also studied. 
Categorical values were expressed as numbers and percentages. Continuous variables were expressed as medians as the samples were small. Analysis was performed using XLstatC (Addinsoft SARL) software.

Results

During the study period, 31 patients with diaphragmatic rupture following blunt trauma were managed in three institutions of the RENAU network. There were 18 men and 13 women; median age was 44 (16-88 years). The median IGSII score was 35 (17-72). Most patients were victims of road accidents, either as the driver or passenger of a motor vehicle $(n=22)$. Twenty-seven ruptures were on the left $(87 \%)$ while four were on the right $(13 \%)$. The diagnosis was made immediately after the accident in 29 patients (93.5\%). Two patients had a delayed presentation, 11 days and three months after the initial trauma, respectively, and in both cases, with a picture of acute respiratory distress. At the time of management, 21 patients (71\%) had respiratory failure (dyspnea, hypoxia), five were asymptomatic, while four presented with isolated thoracic pain. Patient characteristics and mechanisms of injury are summarized in Table 1.

A chest X-ray was performed immediately after hospital admission in 29 patients and led to the diagnosis of diaphragmatic rupture in $18(62 \%)$ thanks to three specific signs, either isolated or in association: (1) air-fluid level image 
(2) interruption of a diaphragmatic cupola border (3) naso-gastric tube in the thorax. The chest X-ray was not suggestive in 11 patients: 10 had non-specific signs (hemothorax, pneumothorax) and one X-ray was interpreted as normal. Thoraco-abdominal CT scan led to the final diagnosis in 29 patients at the time of admission (Figure 2).

Two patients with left diaphragmatic trauma had a delayed presentation. The first had undergone a CT upon admission, performed $1 \frac{1}{2}$ hours after the trauma, but without coronal or sagittal reconstruction; the diagnosis was made on day 11 when a chest X-ray was performed because of onset of respiratory distress. A review of the initial CT scan revealed a minimal diaphragmatic discontinuity. The second patient also presented with acute respiratory distress, three months after the initial trauma, and the diagnosis was made immediately upon interpretation of the new thoraco-abdominal CT scan.

All patients had associated injuries, summarized in Table 2: 26 patients had thoracic injuries (84\%). Most often these were multiple rib fractures on the same side as the diaphragmatic rupture. Seventeen patients had a spinal fracture (55\%) while 15 had a pelvic fracture (48\%).

The median interval between the diagnosis and operative management was 5.5 hours. Six patients underwent operation 48 to $72 \mathrm{~h}$ after the diagnosis, either 
because of life-threatening aortic dissection, spinal or pelvic fracture) or after correction of hemodynamic shock secondary to associated injuries.

Twenty-seven patients underwent a midline laparotomy (23 left-sided and four right-sided ruptures) while three were treated via laparoscopy (three left-sided injuries) and one patient underwent left thoracotomy. The diaphragmatic tear was repaired with simple sutures, figure-of-eight sutures, or continuous sutures, using braided or monofilament non-absorbable material. One female patient with a right-sided injury required concomitant liver packing for venous bleeding from the hepatic dome in a damage-control setting. Seven patients had post-operative complications, one of which was secondary to the diaphragmatic repair: this patient had an incident splenic decapsulation, aggravating an AAST grade III splenic lesion that required splenectomy. Another patient had a compressive pelvic hematoma secondary to pelvic osteosynthesis. All the other complications were medical (ventilator acquired pneumonia, pulmonary embolism and catheter infection). Three patients with left-sided injuries died. In two of these patients, the diagnosis was made immediately upon arrival: one, with severe multiple lesions, died of multi-organ failure soon after operation, while the other died of irreversible brain damage. The third patient, an 88-year-old man with multiple cardiovascular comorbidities, who was diagnosed three months after the initial insult (fall from a 
ladder), died on post-operative day 16 after diaphragmatic repair due to massive pulmonary embolism with cardiorespiratory arrest.

\section{Discussion}

Sudden elevation of intra-abdominal pressure secondary to blunt abdominal trauma can lead to localized rupture of the posterior part of the diaphragm, the embryonic weak spot. Another mechanism can be responsible when the trauma impact is lateral or when there are associated rib fractures, in which the peripheral attachments of the diaphragm are torn $[7,10,15]$ (Figure 3). Diaphragmatic ruptures occur more frequently on the left (65\% of cases); bilateral rupture is exceptional $[1,6]$. The results of our series concur with literature reports as we found that $87 \%$ were left-sided; the left-sided predomination is supported by cadaver studies [16]. Two anatomical factors are advanced to explain the left-sided prevalence: the liver acts as a tamponade on the right [7] and the left half of the diaphragm is weakened by the presence of the hiatal orifice and the lumbo-costal triangle [17].

Focused assessment with sonography for trauma (FAST) and chest X-rays is performed routinely in the unstable patient arriving the emergency room. The use of FAST to detect diaphragmatic rupture has been described in the literature [18] but its practicality seems limited. 
The most specific signs on chest X-rays are the presence of intra-thoracic airfluid level images or the intra-thoracic location of the tip of the nasogastric tube $[7,19-21]$. The elevation of one diaphragmatic cupola in the absence of homolateral atelectasis and the blurred contour of the diaphragm are not specific and are difficult to interpret when other frequently observed concomitant signs are found in the trauma patient such as hemothorax and pneumothorax. The prevalence of positive signs on chest X-ray has been described to range from 3 to $89 \%$ of cases [19-25]. In our population, chest Xray led to the diagnosis in $62 \%$ of patients. Several publications have shown that chest X-ray performances differed according to the side of the rupture, with diagnoses over $50 \%$ of the time when the lesion was on the left, and less than $30 \%$ when the lesion was on the right $[19,20]$. In our small sample, two thirds of chest X-rays led to the diagnosis on the left (16 patients /25) but only to two of four on the right. The rate of missed diagnosis with chest X-ray was $38 \%$ in our series, concordant with the 12 to $66 \%$ range found in the literature $[8]$.

In the trauma patient who is stable or stabilized, total body CT scan with intravenous contrast injection (arterial and portal visualization) is the reference study for diagnosis and workup. CT has been found to perform better than chest X-ray for the diagnosis of diaphragmatic rupture after blunt trauma with 
a sensitivity ranging from 14 to $71 \%$ and a specificity ranging from 76 to $99 \%$ in the literature $[10,26]$. The most pertinent CT signs are intra-thoracic migration of intestinal structures, the collar sign, corresponding to the impingement of the diaphragm on the herniated organ and the "dependent-viscera sign", corresponding to the contact of an intra-abdominal organ with the posterior pleura in the absence of the diaphragmatic barrier [27], and lastly, diaphragmatic discontinuity $[10,26]$. In our series, CT was diagnostic in the 18 patients with specific radiographic signs of rupture on the chest X-rays, and confirmed the rupture in 10 patients who did not have specific radiological signs, as well as in the patient who had a normal chest X-ray (Figure 2). Moreover, in our center, a false diagnosis of diaphragmatic rupture was made in one patient who underwent an exploratory laparoscopy that proved the diagnosis false. Other false-positive CT findings have been described, most often related to postero-lateral defects, found in $6 \%$ of the population, on the left, that correspond to asymptomatic congenital Bochdalek hernia $[7,10]$.

Because of difficulties in making the diagnosis of diaphragmatic rupture $[7,9$, $10,19-21,26]$, the lesion can go undetected for days, months or even years after the trauma [11].

Isolated diaphragmatic rupture after blunt trauma is exceptional [16]. This was also exemplified in our series, where all the patients had at least one other 
injury, thoracic in $84 \%$ spinal in $55 \%$ and pelvic in $48 \%$. This is in accordance with other publications $[1,4,16,23,26]$.

Classical midline laparotomy remains the reference in the unstable patient. In this setting, the diaphragm cupolas should be routinely checked because of the poor diagnostic performance of FAST $[28,29]$ and chest X-ray in the diagnosis of diaphragmatic injury. In the patient who is stable or stabilized, laparoscopy, first described in patients with penetrating trauma [30], then for blunt trauma [31-36], is gaining in popularity, despite initial reluctance related to the risk of air embolism or compressive pneumothorax, that, in fact, have never yet been described in the literature. In our series, three patients underwent laparoscopy, all after 2014 (Figure 4). Another limiting factor for the use of laparoscopy is the difficulty of repair on the right, because of the intervening presence of the liver. In this setting, a thoracoscopic approach could be the solution.

In our center, all diaphragmatic ruptures are repaired as soon as the diagnosis is made. But there are cases when delayed repair is appropriate, for instance in the case of life-threatening associated injuries, as in our series, where the repair was delayed because of the need for endovascular treatment of a ruptured aortic isthmus and splenic embolization. However, in these cases, the diaphragm was always repaired within 72 hours. In our experience, we found 
that the anatomy was favorable for repair when surgery was entertained early. However, some teams advocate delayed repair after several weeks, which can be likened to management of missed injuries [37]. Under these conditions, fibrosis and retraction of the borders of the defect can complicate surgery, requiring adhesiolysis and exposing the patient to difficult repair or the risk of splenectomy. Several artifices have been described in the literature such as repair over pledgets [37] or trans-costal reinsertion of the diaphragm [38], but, in some patients where the primary repair is fragile or when it is difficult to close the defect, use of a prosthesis will be necessary. With regard to the choice of the prosthesis, biological meshes seem to have the same outcome as synthetic mesh repairs $[39,40]$. There are not many publications in the literature concerning the methods of fixation described for these prostheses, but certainly, staples and tackers should be avoided, above all in the peripheral area of the diaphragm. One recent publication has reported 23 cases of tamponade and/or heart injuries after use of these materials for prosthetic fixation near the heart (hiatal hernia repair but also diaphragmatic hernia repair) with a staggering mortality of $50 \%$ [41]

Conclusion

Each and every surgeon who has to manage trauma patients should know the mechanisms of injury, the potential associated injuries, as well as the direct and 
indirect radiological signs that suggest the possibility of diaphragmatic rupture. The diagnostic performance of chest X-ray is mediocre, and the surgeon should search for a loss of diaphragmatic continuity routinely during emergency laparotomy for trauma. In the stable patient, contrast-enhanced total body CT scan with coronal and sagittal reconstructions is the investigation of reference for these patients and can contribute to early timely diagnosis. Repair is most often done via laparotomy but when the diagnosis is not obvious, and when patient status and local conditions permit, laparoscopy is feasible and efficient.

\section{References}

1. Kuo IM, Liao $\mathrm{CH}, \mathrm{H} \sin \mathrm{MC}$ et al. Blunt diaphragmatic rupture--a rare but challenging entity in thoracoabdominal trauma. Am J Emerg Med. 2012;30:919-24.

2. Zarour AM, El-Menyar A, Al-Thani H, Scalea TM, Chiu WC. Presentations and outcomes in patients with traumatic diaphragmatic injury: a 15-year experience. J Trauma Acute Care Surg. 2013;74:1392-8.

3. Ties JS, Peschman JR, Moreno A et al. Evolution in the management of traumatic diaphragmatic injuries: a multicenter review. J Trauma Acute Care Surg. 2014;76:1024-8. 
4. Fair KA, Gordon NT, Barbosa RR, Rowell SE, Watters JM, Schreiber MA. Traumatic diaphragmatic injury in the American College of Surgeons National Trauma Data Bank: a new examination of a rare diagnosis. Am J Surg. 2015;209:864-8; discussion 868-9.

5. Shah R, Sabanathan S, Mearns AJ, Choudhury AK. Traumatic rupture of diaphragm. Ann Thorac Surg. 1995;60:1444-9.

6. Lopez PP, Arango J, Gallup TM et al. Diaphragmatic injuries: what has changed over a 20-year period? Am Surg. 2010;76:512-6.

7. lochum S, Ludig T, Walter F, Sebbag H, Grosdidier G, Blum AG. Imaging of diaphragmatic injury: a diagnostic challenge? Radiographics. 2002;22 Spec No:S103-16; discussion S116-8.

8. Reber PU, Schmied B, Seiler CA, Baer HU, Patel AG, Büchler MW. Missed diaphragmatic injuries and their long-term sequelae. J Trauma. 1998;44:183-8.

9. Dirican A, Yilmaz M, Unal B, Piskin T, Ersan V, Yilmaz S. Acute traumatic diaphragmatic ruptures: A retrospective study of 48 cases. Surg Today. 2011;41:1352-6.

10.Sangster G, Ventura VP, Carbo A, Gates T, Garayburu J, D'Agostino H. Diaphragmatic rupture: a frequently missed injury in blunt thoracoabdominal trauma patients. Emerg Radiol. 2007;13:225-30. 
11.Rashid F, Chakrabarty MM, Singh R, Iftikhar SY. A review on delayed presentation of diaphragmatic rupture. World J Emerg Surg. 2009;21;4:32.

12.Letoquart JP, Kunin N, Lechaux D, Gerard O, Morcet N, Mambrini A. Rupture of the diaphragm in closed traumas: a 7,propos of 28 cases. J Chir (Paris). 1995;132:478-82.

13. Cougard P, Goudet P, Arnal E, Ferrand F. Treatment of diaphragmatic ruptures by laparoscopic approach in the lateral position. Ann Chir. 2000;125:238-41.

14. Bouzat P, Broux C, Ageron FX et al. Trauma network for severely injured patients. Ann Fr Anesth Reanim. 2013;32:531-4.

15.Kearney PA, Rouhana SW, Burney RE. Blunt rupture of the diaphragm: mechanism, diagnosis, and treatment. Ann Emerg Med. 1989;18:132630.

16. McElwee TB, Myers RT, Pennell TC. Diaphragmatic rupture from blunt trauma. Am Surg. 1984;50:143-9.

17. Bosanquet D, Farbouda A, Luckrazb H. A review diaphragmatic injury. Respir Med CME. 2009;1:1-6.

18.Gelman R, Mirvis SE, Gens D. Diaphragmatic rupture due to blunt trauma: sensitivity of plain chest radiographs. AJR Am J Roentgenol. 1991;156:51-7.

19.Shapiro MJ, Heiberg E, Durham RM, Luchtefeld W, Mazuski JE. The unreliability of CT scans and initial chest radiographs in evaluating blunt trauma induced diaphragmatic rupture. Clin Radiol. 1996;51:27-30.

20.Pikoulis E, Delis S, Scandalakis P et al. Reliability of initial chest radiographs in the diagnosis of blunt diaphragmatic rupture. Ann Chir Gynaecol. 2000;89:10-3. 
21.Chughtai T, Ali S, Sharkey P, Lins M, Rizoli S. Update on managing diaphragmatic rupture in blunt trauma: a review of 208 consecutive cases. Can J Surg. 2009;52:177-81.

22. Hanna WC, Ferri LE, Fata P, Razek T, Mulder DS. The current status of traumatic diaphragmatic injury: lessons learned from 105 patients over 13 years. Ann Thorac Surg. 2008;85:1044-8.

23. Mihos P, Potaris K, Gakidis J et al. Traumatic rupture of the diaphragm: experience with 65 patients. Injury. 2003;34:169-72.

24.Ozpolat B, Kaya O, Yazkan R, Osmanoğlu G. Diaphragmatic injuries: a surgical challenge. Report of forty-one cases. Thorac Cardiovasc Surg. 2009;57:358-62.

25. Hammer MM, Flagg E, Mellnick VM, Cummings KW, Bhalla S, Raptis CA. Computed tomography of blunt and penetrating diaphragmatic injury: sensitivity and inter-observer agreement of CT Signs. Emerg Radiol. 2014;21:143-9.

26.Bonatti M, Lombardo F, Vezzali N, Zamboni GA, Bonatti G. Blunt diaphragmatic lesions: Imaging findings and pitfalls. World J Radiol. 201628;8:819-828.

27. Blaivas M, Brannam L, Hawkins M, Lyon M, Sriram K. Bedside emergency ultrasonographic diagnosis of diaphragmatic rupture in blunt abdominal trauma. Am J Emerg Med. 2004;22:601-4.

28.Gangahar R, Doshi D. FAST scan in the diagnosis of acute diaphragmatic rupture. Am J Emerg Med. 2010;28:387.e1-3.

29.Cantwell CP. The dependent viscera sign. Radiology. 2006;238:752-3.

30.Goudet P, Cheynel N, Ferrand L et al. Lateral approach to laparoscopic repair of left diaphragmatic ruptures. World J Surg. 2001;25:1150-4. 
31.Murray JA, Demetriades D, Asensio JA et al. Occult injuries to the diaphragm: prospective evaluation of laparoscopy in penetrating injuries to the left lower chest. J Am Coll Surg. 1998;187:626-30.

32. Matz A, Landau O, Alis M, Charuzi I, Kyzer S. The role of laparoscopy in the diagnosis and treatment of missed diaphragmatic rupture. Surg Endosc. 2000;14:537-9.

33. Meyer G, Hüttl TP, Hatz RA, Schildberg FW. Laparoscopic repair of traumatic diaphragmatic hernias. Surg Endosc. 2000;14:1010-4.

34.Matthews BD, Bui $\mathrm{H}$, Harold KL et al. Laparoscopic repair of traumatic diaphragmatic injuries. Surg Endosc. 2003;17:254-8.

35.Justin V, Fingerhut A, Uranues S. Laparoscopy in Blunt Abdominal Trauma: for Whom? When? and Why? Curr Trauma Rep. 2017;3:43-50.

36.F RECHE, B BADIC, J ABBA, D VOIRIN, C GOURLE, E MOSCOSO, G MULIERI, C LETOUBLON, C ARVIEUX. Intérêt de la laparoscopie différée dans la gestion des traumatismes abdominaux fermés. Journal de Coeliochirurgie 2010, 9:5-10

37.Goudet P, Cheynel N, Ferrand L et al. Lateral approach to laparoscopic repair of left diaphragmatic ruptures. World J Surg. 2001;25:1150-4.

38. Liao $\mathrm{CH}, \mathrm{Chu} \mathrm{CH}, \mathrm{Wu}$ YT et al. The feasibility and efficacy of laparoscopic repair for chronic traumatic diaphragmatic herniation: introduction of a novel technique with literature review. Hernia. 2016;20:303-9.

39.Kamiyoshihara $\mathrm{M}$, Igai $\mathrm{H}$, Kawatani $\mathrm{N}$, Ibe T. A minimally invasive technique for stabilizing the diaphragm on the thoracic wall after blunt chest trauma: the "lifting-up method". Surg Today. 2016;46(7):872-5. 40.Al-Nouri O, Hartman B, Freedman R, Thomas C, Esposito T. Diaphragmatic rupture: Is management with biological mesh feasible? Int J Surg Case Rep. 2012;3:349-53. 
41.Antoniou SA, Pointner R, Granderath FA, Köckerling F. The Use of Biological Meshes in Diaphragmatic Defects - An Evidence-Based Review of the Literature. Front Surg. 2015;21;2:56.

42. Köckerling F, Schug-Pass C, Bittner R. A word of caution: never use tacks for mesh fixation to the diaphragm! Surg Endosc. 2018;32:3295-3302. 
Table 1. Patient characteristics $(n=31)$

Median age (years)

$44(16-88)$

Gender

Male

18

Female

13

Mechanism of injury

Motor vehicle road

accident

22

Fall (one patient fell

from a window)

3

Two wheel vehicle road

accident

2

Snowboard

1

Crush injury (crane)

1

Pedestrian

1

Paraglider

1

IGSII score (Median)

35 (17-72)

Side of injury

Left

27

Right

4 
Table 2. Associated injuries

$$
\text { n } \% \text { Examples }
$$

Thorax

26 84\% Rib fractures: 24

Hemothorax: 6

Pneumothorax: 7

Sternal fracture: 4

Spine

17 55\% Transverse apophysal fracture: 11

Vertebral body fractures: 6

Pelvis

15 48\% Ilio-pubic ramus: 8

Ischio-pubic ramus: 8

Acetabular fracture: 6

Iliac wing fracture: 3

Sacral fracture: 3

Limbs

15 48\% Lower limb fractures: 9

Upper limb fractures: 8

Gastrointestinal tract

8 26\% Mesenteric injury: 2

Small intestinal and colonic perforation: 4

Gastric perforation: 1

Duodenal hematoma: 1

Spleen

$8 \quad 26 \%$ AAST Grade III: 4

AAST Grade IV: 4

Cerebral

5 16\% Diffuse axonal lesions: 2

Hemorrhagic petechia: 2

Sub-arachnoid bleeding: 1 
Liver

Kidney

Thoracic aorta
3 10\% AAST Grade I: 2

AAST Grade IV: 1

$26 \%$ AAST Grade I: 1

AAST Grade II: 1

$26 \%$ Grade II traumatic dissection: 2

Figure 1. Decisional algorithm for management of polytrauma patient with the diagnosis of diaphragmatic rupture.

Figure 2. Pre-operative CT scans: Image A: 44-year old man having sustained a motor vehicle road accident. The $\mathrm{CT}$ shows a left diaphragmatic injury with intra-thoracic migration of the splenic flexure (open arrow). Image B: 31-yearold man having sustained a motor vehicle road accident. The CT shows a left diaphragmatic rupture with gastric collar sign (full arrow) and dependentviscera sign (open arrow). Images C, D and E: 21 year-old man having sustained 
a motorcycle road accident. The CT shows a left diaphragmatic hernia with collar sign and dependent-viscera sign (respectively full and open arrows in C), discontinuity of diaphragm (double arrow in D). Sagittal reconstruction identifies the rupture (E). Image F: 3-D reconstruction of CT in an 88-year-old man presenting with left diaphragmatic rupture and intra-thoracic gastric migration.

Figure 3. Mechanisms and types of post-traumatic diaphragmatic rupture (inferior view). 1: torn peripheral attachments of the diaphragm (right crus in the figure). 2: Central rupture (right anterior muscular portion in the figure). 3: transversal rupture located in the diaphragmatic dome (left anterior tendon portion in the figure). 4: Postero-lateral rupture (left muscular portion in the figure).

Figure 4. Intra-operative view during laparoscopy in an 18 year-old woman following a motor vehicle road accident. The chest X-ray and CT scan were indicative of a left diaphragmatic rupture. Image A: View of the rupture showing the pericardium. Image B: View of the rupture showing the left inferior pulmonary lobe and intra-thoracic ascension of the omentum. Image C: Reconstitution of the rupture and tear of the left triangular ligament. Image D: final view after repair by two running sutures of non-absorbable braided suture material. 


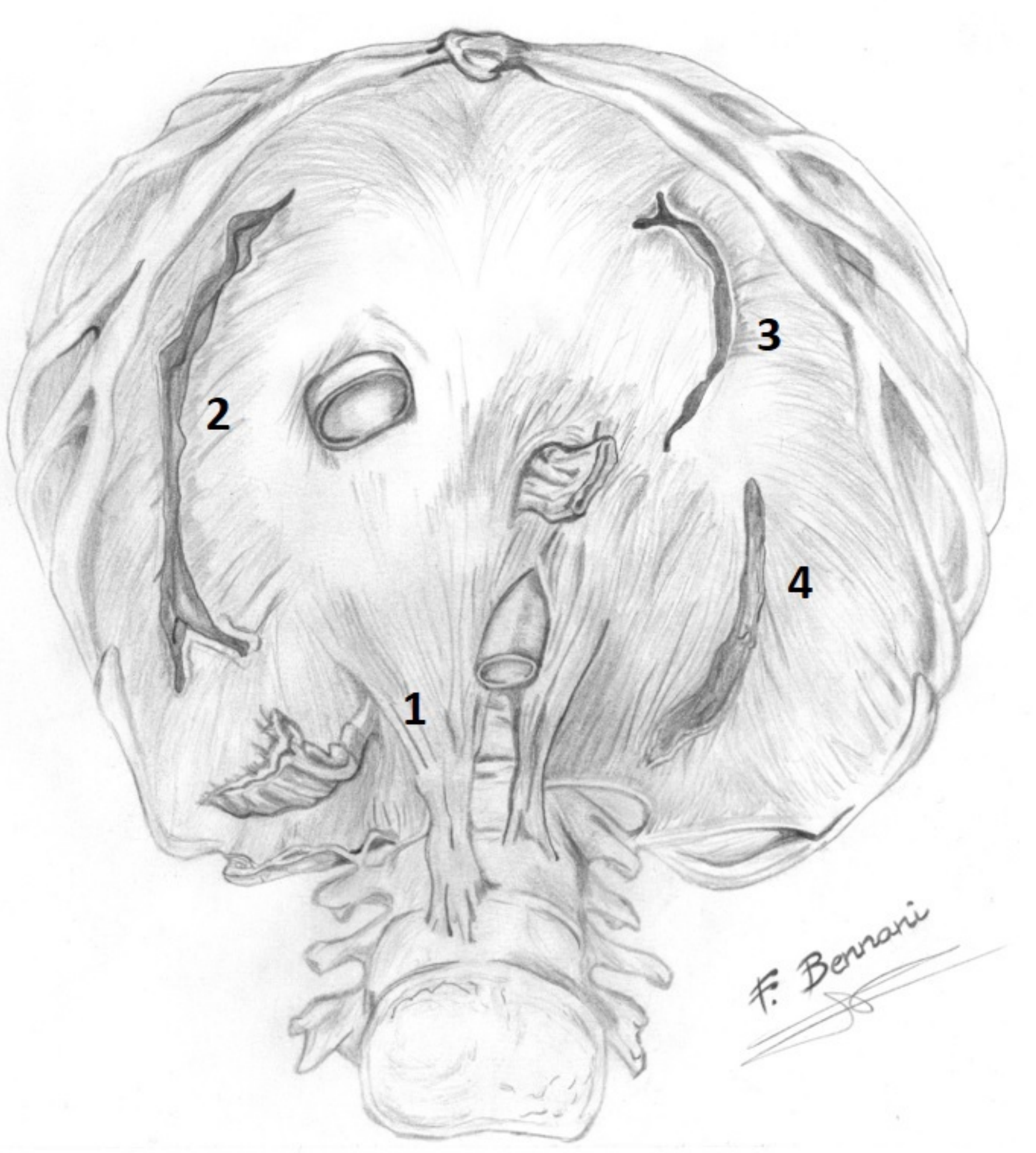


$\mathbf{A}$

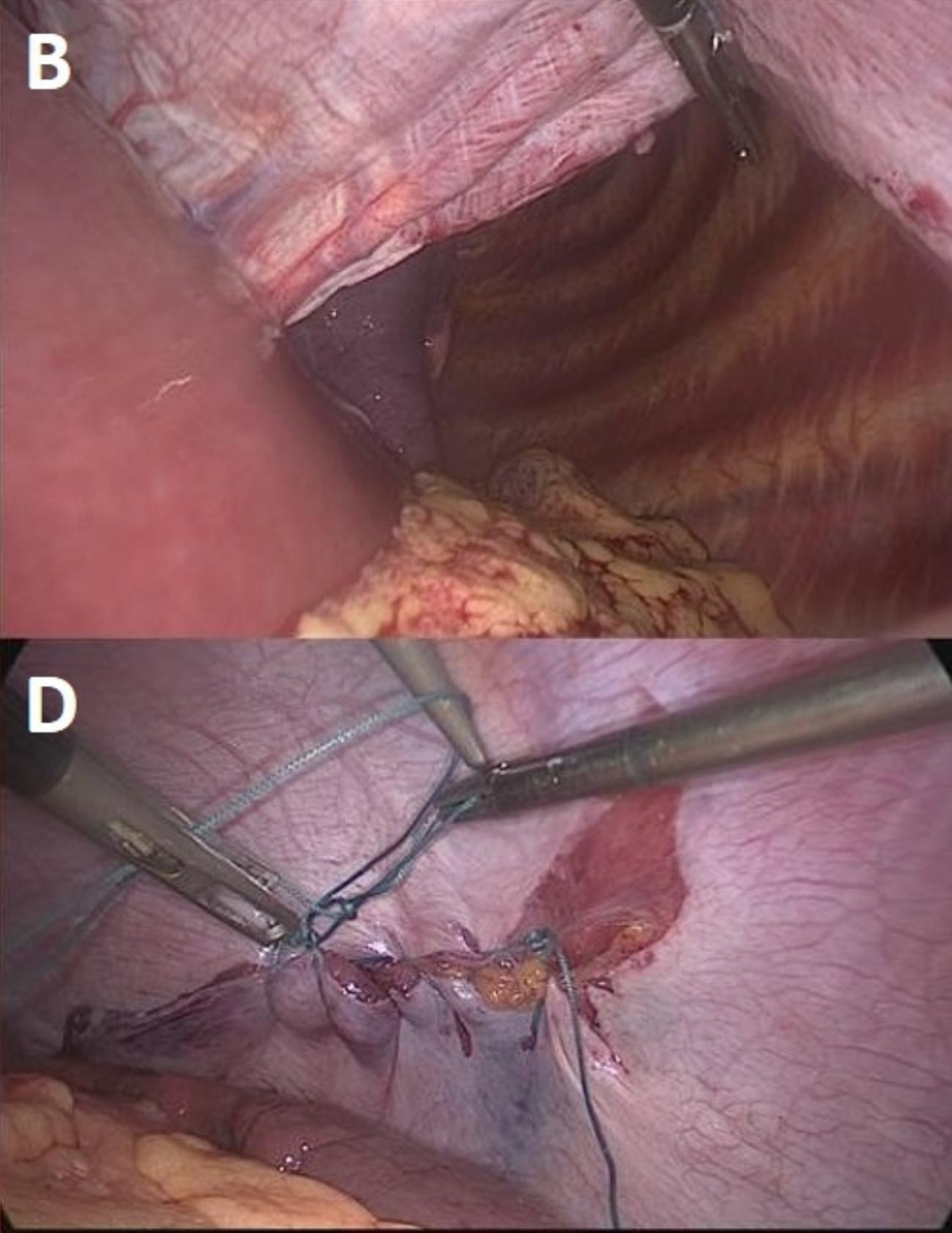




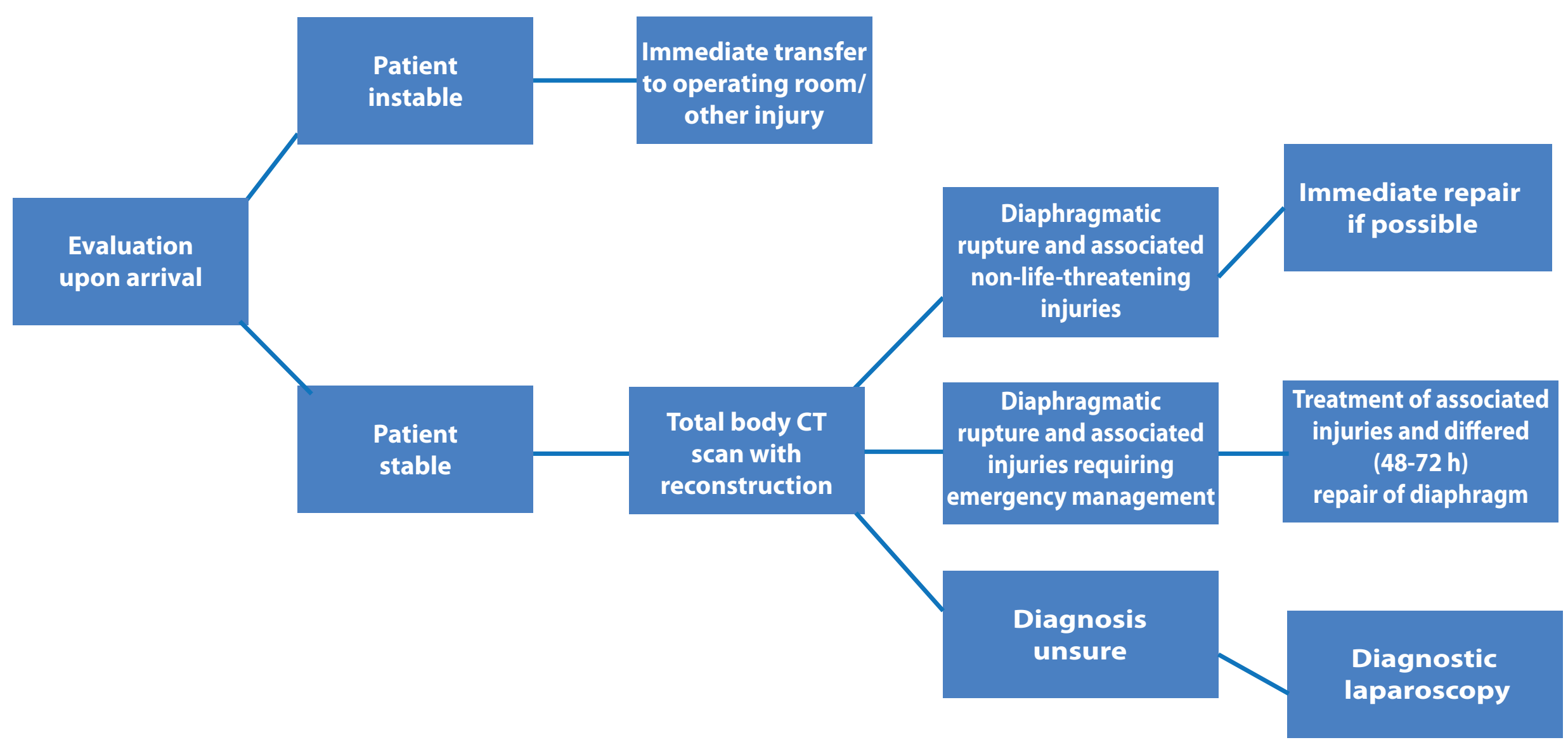

